\title{
Brexit and Uncertainty: Insights from the Decision Maker Panel
}

\author{
Nicholas Bloom, ${ }^{(1)}$ Philip Bunn, ${ }^{(2)}$ Scarlet Chen, ${ }^{(3)}$ Paul Mizen, ${ }^{(4)}$ Pawel Smietanka, ${ }^{(5)}$ \\ Greg Thwaites, ${ }^{(6)}$ and Garry Young ${ }^{(7)}$
}

\begin{abstract}
The UK's decision to leave the EU in the 2016 referendum created substantial uncertainty for UK businesses. The nature of this uncertainty is different from that of a typical uncertainty shock because of its length, breadth and political complexity. Consequently, a new firm-level survey, the Decision Maker Panel (DMP), was created to investigate this, finding three key results. First, Brexit was reported to be one of the top three sources of uncertainty for around 40 per cent of UK businesses in the two years after the vote in June 2016 referendum. This proportion increased further in autumn 2018. Hence, Brexit provided both a major and persistent uncertainty shock. Second, uncertainty has been higher in industries that are more dependent on trade with the EU and on EU migrant labour. Third, the uncertainties around Brexit are primarily about the impact on businesses over the longer term rather than shorter term, including uncertainty about the timing of any transition arrangements and around the nature of Brexit.
\end{abstract}

Keywords: business surveys, Brexit, companies, uncertainty.

JEL classification: D80, E66, G18, H32.

(1) Stanford University. Email: nbloom@stanford.edu

(2) Bank of England.Email: philip.bunn@bankofengland.co.uk

(3) Stanford University.Email: sijiac@stanford.edu

(4) University of Nottingham.Email:paul.mizen@nottingham.ac.uk

(5) Bank of England. Email: pawel.smietanka@bankofengland.co.uk

(6) LSE Centre for Macroeconomics. Email: g.d.thwaites@lse.ac.uk

(7) National Institute of Economic and Social Research.Email: g.young@niesr.ac.uk

This paper was finalised in late October 2018 using data available up to 22 October 2018. The views expressed in this paper do not necessarily represent those of the Bank of England or its Committees. The authors would like to thank the Economic and Social Research Council for financial support (grant number ES/P010385/1). They also thank Steve Davis from University of Chicago Booth School of Business as well as David Altig, Brent Meyer and Nicholas Parker from the Atlanta Fed for sharing their experience on conducting the Atlanta Fed Survey of Business Uncertainty, which the authors greatly benefited from. Further, they would like to thank participants at conferences/seminars hosted by the Banque de France, Banca d'Italia and Sciences Po in Paris, the Economic Statistics Centre of Excellence (ESCoE), Philadelphia Fed and University of Chicago for useful comments and suggestions. Finally, they would like to thank Stefania Spiga for her assistance in running the survey as well as Kate Fisher, Julia Leather and the recruitment team for their crucial involvement in the project. 


\section{Introduction}

The UK's decision to leave the European Union (EU) in the June 2016 referendum created substantial uncertainty for UK businesses. There are a number of different aspects to this uncertainty - for example, around what the UK's eventual relationship with the EU will look like and how this will affect things such as market access, the availability of migrant labour and product regulation. However, there is also uncertainty around how the UK will transition to that new end state, how the relationship will look at different points in time and what each of these will mean for the prospects of individual businesses. Understanding these different aspects of that uncertainty is crucial to be able to assess how companies might respond and what the implications for the macroeconomy might be. The unique nature of the uncertainty presented by Brexit limits the extent to which the existing literature or data sets can be used to inform such an assessment. New approaches are required to better understand the impact of Brexit on firms' behaviour. The Decision Maker Panel (DMP) is a new and novel firm-level data set that was instigated specifically to help better understand the uncertainties associated with Brexit. This paper uses data from the DMP to investigate what we have learnt about the uncertainties that Brexit has created for British businesses up to the point that the paper was finalised in late October 2018.

There is a wide literature that shows how uncertainty can affect macroeconomic outcomes. This is based around the idea that uncertainty increases the incentive to delay investment because it increases the real option value of waiting. ${ }^{1}$ A range of different indicators have been used to measure uncertainty, such as stock market volatility ${ }^{2}$ or media reports, ${ }^{3}$ and the link between these types of data and activity has been well established. However, these measures do not clearly distinguish between effects on different firms and they provide conflicting messages about what has happened to uncertainty since the EU referendum. Media-report-based measures rose to unprecedented levels whilst there was very little increase in other uncertainty measures such as stock market volatility. This highlights the challenge of how to understand the uncertainties associated with Brexit. But there are many other challenging aspects to this too which are not captured by previous studies the uncertainty surrounding Brexit is longer term in nature, whilst uncertainty shocks typically tend to be quite short-lived etc. Brexit is likely to involve more Knightian uncertainty because there are so many unknowns that are difficult for businesses to quantify. Another unique aspect to the uncertainty around Brexit is that it is likely to be closer to a pure second-moment uncertainty shock than most previous shocks, which are often associated with recessions. This is particularly the case during the period before the UK actually leaves the $\mathrm{EU}$, given that the impacts of Brexit should be primarily longer term in nature, although there may still have been anticipation-type effects that have had a modest impact on activity, relative to what would have otherwise been the case.

\footnotetext{
${ }^{1}$ Dixit and Pindyck, 1994.

${ }^{2}$ For example, Bloom, 2009

${ }^{3}$ Baker, Bloom and Davis, 2016.
} 
To help better understand the uncertainties created by Brexit and how they have affected UK businesses, the Bank of England together with Stanford University and the University of Nottingham launched the Decision Maker Panel in August 2016. This is a new large and representative business survey that collects information on many different aspects of uncertainty. These include: (i) self-reported views about the importance of Brexit as a source of uncertainty to each business; (ii) uncertainty about the eventual impact on the sales and costs of each business; (iii) uncertainty about year-ahead sales growth; and (iv) uncertainty about the timing of Brexit after any transition period. The survey is closely based on the Survey of Business Uncertainty run in the US by the Atlanta Fed, which is described in Altig et al. (2018). We greatly benefited from the experience shared by colleagues involved in that survey.

Our contribution focuses on addressing a number of important questions. These include: (i) the extent to which Brexit has generated uncertainty for firms; (ii) the types of firms that have been most affected; (iii) the nature of this uncertainty; and (iv) how this has changed since the referendum. This paper does not focus on how businesses have responded to these uncertainties. We leave that for future work.

To summarise our main results, we find that Brexit has been an important source of uncertainty for around 40 per cent of UK businesses for most of the period since the referendum. Uncertainty has typically been higher in industries that are more dependent on trade with the EU and on EU migrant labour. DMP responses suggest that the uncertainties around Brexit are primarily about the impact on businesses over the longer term and are less about the implications in the short term whilst the UK remains a member of the EU. We provide evidence that businesses are uncertain about the impact that Brexit will have on their sales, exports and costs over the longer term as well as about the timing of any transition arrangements. In the first two years after the referendum, there were not any large changes in the uncertainties that businesses faced as the Brexit negotiations evolved, although uncertainty did increase in autumn 2018 (at least up until the point this article was finalised in late October) as the date at which the UK is due to leave the EU approached without a deal yet being agreed.

The structure of the paper is as follows. Section II looks briefly at the literature on uncertainty and draws out what that might be able to reveal about Brexit. Section III provides a short overview of the Decision Maker Panel before Section IV discusses what the results from that survey can tell us about Brexit uncertainty. Section V concludes. 


\section{Insights from the literature}

Before we consider some evidence on uncertainty and Brexit, we first briefly explore the reasons in the literature for why uncertainty is likely to influence economic outcomes and the associated empirical evidence.

\section{(i) Real options}

If firms look at investment decisions as a series of real options, ${ }^{4}$ then uncertainty may incline firms to wait for more information or greater clarity. The option value of a delay is greater when uncertainty is high, and this makes firms cautious about costly actions such as investment that are hard to reverse. In most investment decisions, there are fixed costs that cannot be recovered if the project is abandoned. Assuming that the firm has the luxury of being able to wait, the real options theory implies firms will invest less when uncertainty occurs and will delay their decision until new information arrives to clarify the situation.

The real options argument implies that uncertainty reduces the level of investment and also reduces the sensitivity of investors to changes in business conditions, weakening the effectiveness of policy to counter cycles in real economic activity. When uncertainty is high, productive firms are less aggressive in expanding and unproductive firms are less aggressive in contracting, making both types of firms more cautious. Nor do they respond as readily to changes in monetary or fiscal policy. Bloom (2014) refers to this as a "chilling effect' on investment and productivity, which explains why uncertainty can drive business cycles. ${ }^{5}$

\section{(ii) Risk aversion and risk premiums}

Greater uncertainty increases the risks associated with any investment project - particularly since the pay-off required to make the project profitable is less certain. The financial backers of the investment will typically seek compensation for bearing the higher risk and, because greater uncertainty leads to increasing default risk, they will also demand a higher default premium. This combines to raise the costs of borrowing in uncertain times and particularly influences firms that are financially constrained. ${ }^{6}$

Uncertainty affects consumers as well as investors and, in the face of greater uncertainty, consumers may increase their precautionary saving, which reduces consumer demand. ${ }^{7}$ This effect is likely to be contractionary for an economy in the short run. In open economies, some of the increased saving will leak to foreign countries, which Fernández-Villaverde et al. (2011) argue will lower economic growth, producing a further reduction in demand. In the worst case, consumers may be so uncertain that they cannot form a probability distribution and this will lead to 'ambiguity aversion', which causes them to act as if the worst outcome will occur.

\footnotetext{
${ }^{4}$ Bernanke, 1983; Brennan and Schwartz, 1985; McDonald and Siegel, 1986.

${ }^{5}$ Bloom et al., 2018.

${ }^{6}$ Christiano, Motto and Rostagno, 2014; Gilchrist, Sim and Zakrajšek, 2014; Arellano, Bai and Kehoe, 2018.

${ }^{7}$ Bansal and Yaron, 2004.
} 


\section{(iii) Empirical evidence on the effects of uncertainty}

Bloom (2014) shows that macroeconomic indicators of uncertainty tend to be countercyclical and rise during recessions and after a significant economic shock. For example, the VIX index of 30-day implied volatility (on the S\&P 500 index), disagreement amongst professional forecasters, the size of forecast errors ${ }^{8}$ and conditional variance from GARCH models ${ }^{9}$ all typically rise in recessions.

The link between various measures of macroeconomic uncertainty and activity has been well established, at both the aggregate and firm levels. At an aggregate level, vector autoregression (VAR) models are commonly used to estimate the effects of uncertainty on the economy. Figure 1, taken from Baker, Bloom and Davis (2016), is one such example. ${ }^{10}$ It illustrates how uncertainty is typically estimated to have much larger impacts on investment than on consumption, although given their relative weights in GDP (around six to one in the UK), the effects on consumption still form an important part of the GDP effect. The effects on the level of investment tend to come through relatively quickly, with the peak impact on the level being within a year of the shock, but they are less persistent than effects on consumption. At the firm level, several studies show that greater uncertainty affects various business decisions. ${ }^{11}$

Figure 1: Impact of a policy uncertainty shock

Percentage impact

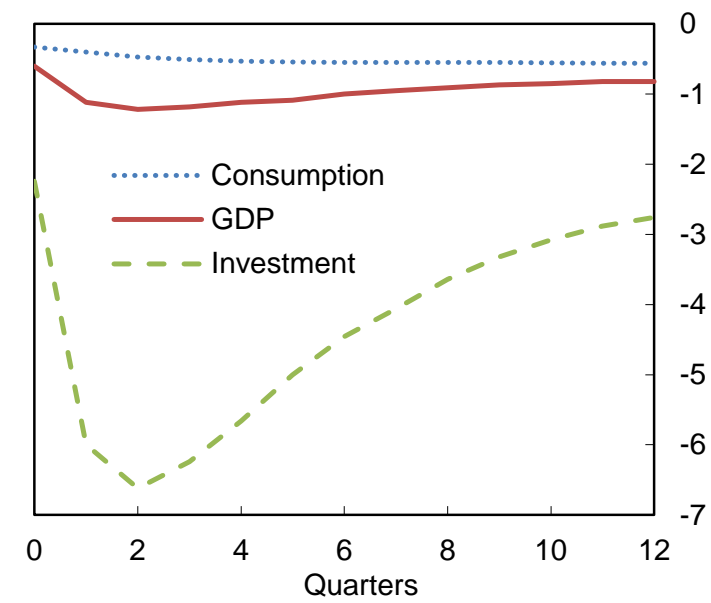

Source: Baker, Bloom and Davis, 2016.

\section{Figure 2: Measures of uncertainty}

Standard deviations from average since 1997

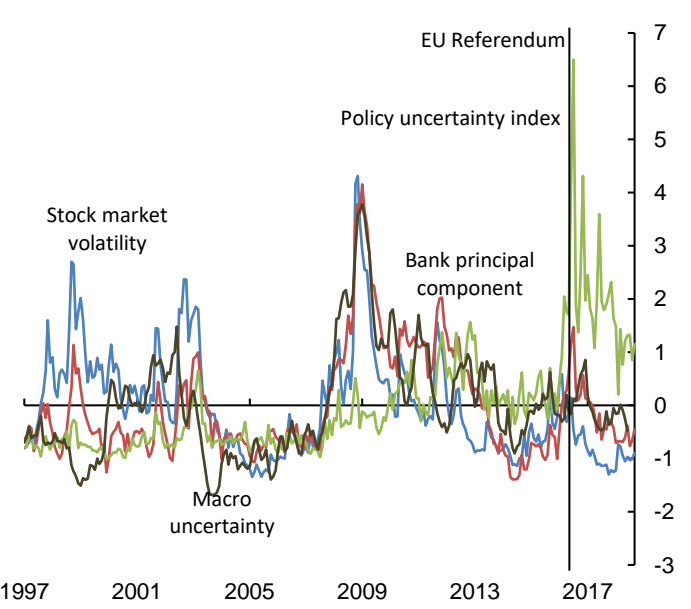

Source: Bloomberg, Consensus Economics, Dow Jones Factiva, GfK (research on behalf of the European Commission), Thomson Reuters Datastream, www.policyuncertainty.com and authors' calculations.

Notes: 'Stock market volatility' measure is FTSE all-share three-month option implied volatility. 'Bank principal component index' is the first principal component extracted from the following indicators: the average standard deviation of monthly Consensus Economics forecasts for GDP growth in the current and next year ahead, seasonally adjusted by Bank of England staff; the number of media reports citing uncertainty in four national broadsheet newspapers; and survey responses of households to questions relating to their personal financial situation and unemployment expectations. 'Policy uncertainty index' is constructed based on newspaper articles regarding policy uncertainty in The Times and The Financial Times. 'Macro uncertainty' is taken from Redl (2017) and was updated by the author on request.

\footnotetext{
${ }^{8}$ Jurado, Ludvigson and Ng, 2015; Scotti, 2016.

${ }^{9}$ Fountas and Karanasos, 2007.

${ }^{10}$ Using a VAR estimated on monthly US data, this shows the impact of an increase in the policy uncertainty index from its average value in $2005-06$ to its average in 2011-12.

${ }^{11}$ Guiso and Parigi, 1999; Alfaro, Bloom and Lin, 2018; Smietanka, Bloom and Mizen, 2018.
} 


\section{(iv) Developments in uncertainty indicators since Brexit}

Different uncertainty indicators have provided conflicting messages since the Brexit referendum. The policy uncertainty index, developed by Baker, Bloom and Davis (2016) based on media reports, rose to unprecedented levels following the referendum, far exceeding the levels reached during the financial crisis and euro area crisis (see Figure 2). But at the same time there was very little increase in stock market volatility (also shown on Figure 2). Other indicators that combine a range of macro data were in between the two but do not imply that Brexit was a historically large uncertainty shock (Figure 2 also shows a principal-componentbased measure used by the Bank of England and described by Haddow et al. (2013) and a measure of macro uncertainty that estimates the conditional variance of the unforecastable component common to a large number of macroeconomic variables, of the type suggested by Jurado, Ludvigson and $\mathrm{Ng}$ (2015) and estimated for the UK by Redl (2017)).

The divergence between different measures of aggregate uncertainty highlights the challenge of understanding the uncertainties associated with Brexit. It is hard to quantify the importance of Brexit-related uncertainty using the existing literature given the divergence of the different indicators discussed above and the fact that the uncertainty surrounding Brexit is different from previous large uncertainty shocks - for example, by being longer term in nature, not being associated with a recession and being about the nature of the UK's trading relationships. More comprehensive information is required. That ideally needs to be at the firm level since companies with different characteristics will be affected in different ways. To help address this and to allow the effects of Brexit to be properly understood, we instigated the Decision Maker Panel - a new quarterly survey of UK-based companies.

As we discuss in more detail in the next section, the DMP collects information on many different types of uncertainty - for example, around how many businesses see Brexit as an important source of uncertainty, uncertainty around the type of Brexit deal that will be agreed, uncertainty about how that will affect individual businesses and uncertainty around year-ahead sales. Doing this using a large and representative sample allows the results to be disaggregated in order to help understand the effects on different types of businesses. And because the survey is high frequency, it can also be used to track how these uncertainties evolve over time. The remainder of this paper describes the DMP, the type of data that are being collected, the methods we use to elicit information about uncertainty and what we have learnt about that uncertainty so far.

\section{The Decision Maker Panel}

The Decision Maker Panel was launched in August 2016 by the Bank of England, Stanford University and the University of Nottingham. The survey also benefits from financial support from the Economic and Social Research Council. It is designed to be representative of the UK business population, covering large, medium and small firms from across the economy. The size of the panel has grown rapidly since its inception, reaching 
6,200 firms employing around 4 million people by October 2018 (Figure 3). This corresponds to about 15 per cent of all private sector employee jobs in the UK. The monthly response rate has averaged 54 per cent since the survey was launched and 44 per cent in 2018. DMP members are asked regular questions about developments in, and the probabilities that they ascribe to, a range of possible future outcomes in the following areas: investment; employment; sales; and prices. Regular questions asked in the survey are similar to the questions asked in the Atlanta Fed's Survey of Business Uncertainty and described in Altig et al. (2018). These regular questions have been supplemented by special questions that have primarily focused on the possible impact of Brexit. The survey contains data on several different aspects of Brexit uncertainty, such as: views about the importance of Brexit as a source of uncertainty to each business; information on uncertainty around the eventual impact on the sales and other aspects of individual businesses; and data on uncertainty about year-ahead sales growth. It has included questions about the predicted timing of Brexit and uncertainty surrounding firms' predictions. The results from many of these questions are discussed below.

\section{Figure 3: DMP sample size}

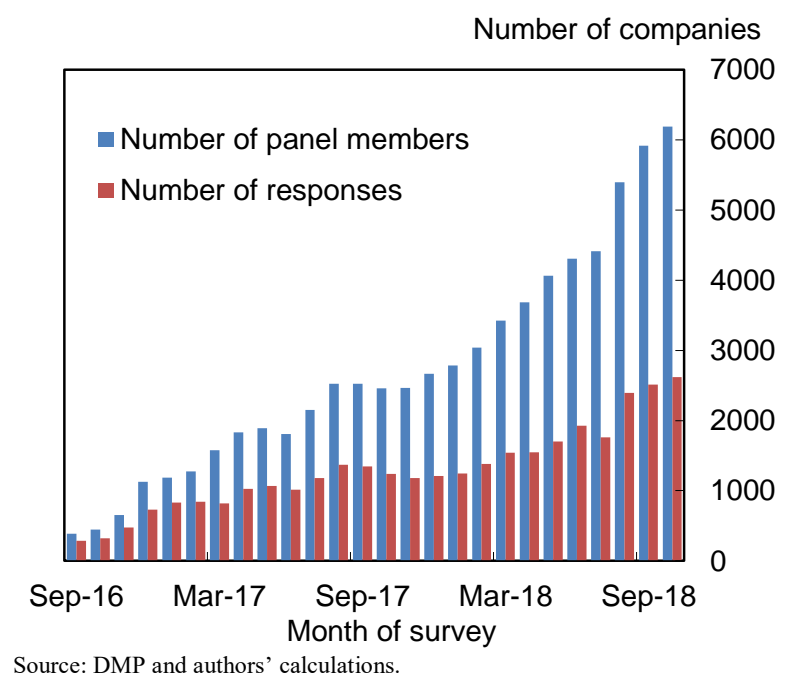

The DMP has several advantages relative to other surveys: it contains a range of subjective uncertainty questions; it is representative of the UK business population; it has a large sample size (so can be split by region, industry or firm size); it is quantitative; and it is timely, with responses made available to policymakers within days of being collected.

The sampling frame for the DMP was selected from a database containing information that all UK companies must submit annually to Companies House. ${ }^{12}$ All active companies with at least 10 employees, which were not a subsidiary of a UK parent company and which had a complete set of company accounts data information were eligible for selection. Chief Financial Officers (CFOs) of these companies were contacted by a recruitment team based at the University of Nottingham and asked whether they would like to participate.

\footnotetext{
${ }^{12}$ Companies House is the agency responsible for maintaining a register of all active companies in the UK. All forms of companies are legally required to register and supply information about the company. The sample was drawn using the Bureau van Dijk database.
} 
Those who agreed are sent a short web-based survey on a monthly basis. The surveys have a rotating panel structure, with each member being asked one-third of the quarterly questionnaire each month. ${ }^{13}$ Figures 4 and 5 show the DMP provides good coverage of different industries and firm sizes, although the data are still weighted to match up to the Business Register to ensure that they provide a fully representative view. ${ }^{14}$ Further details on the survey methodology can be found in Bloom et al. (2017).

Figure 4: Employment by industry

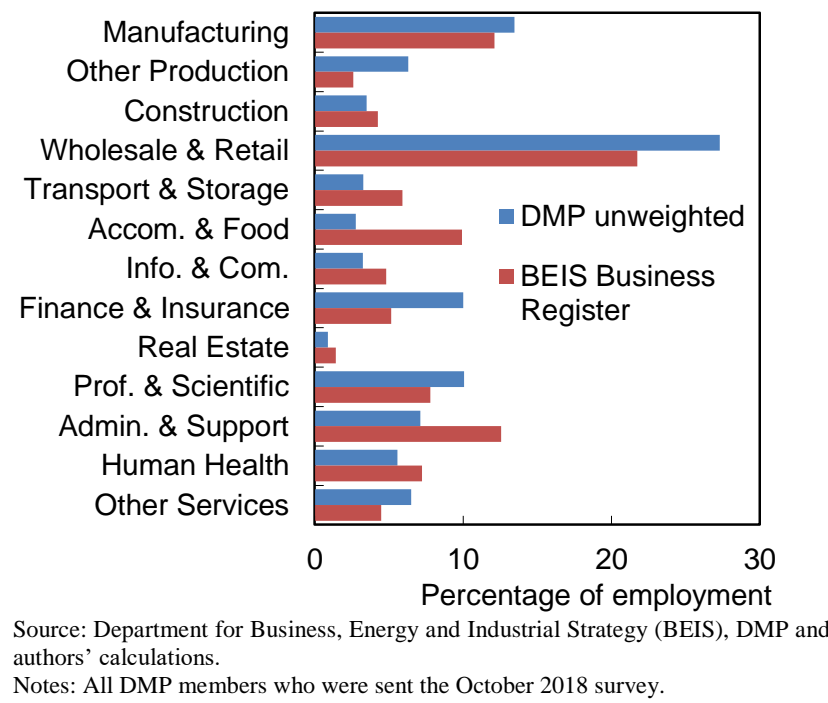

Figure 5: Employment by firm size

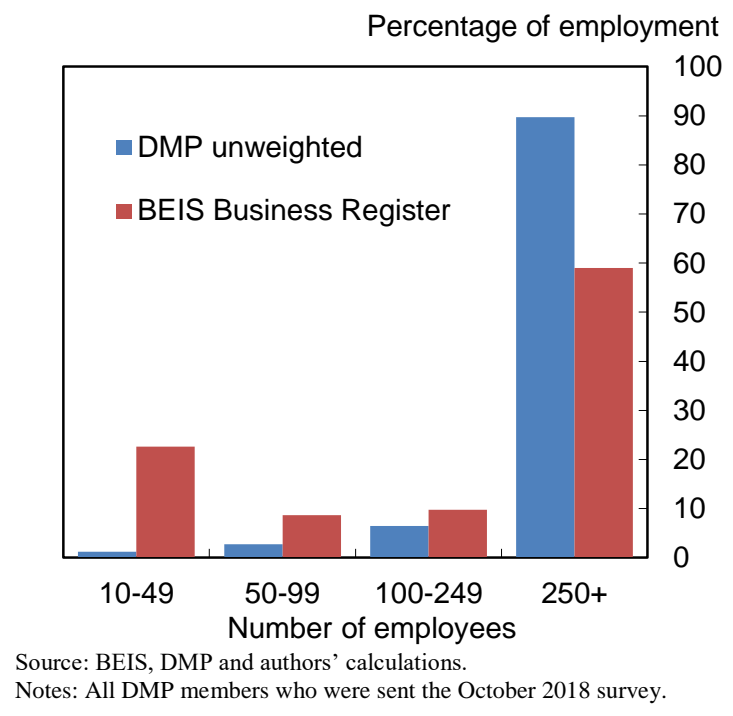

As well as being representative of the business population in terms of covering businesses of different sizes and in different industries, it is important that the survey is not biased towards businesses or individuals who are particularly in favour of or against Brexit, relative to the wider population. To investigate this, we have asked panel members about their personal view on Brexit at the time of the referendum. About a quarter of panel members reported that they were positive about Brexit and about three-quarters were negative (Figure 6). The share of panel members who were negative about Brexit was higher than the share in the wider population, where only 48 per cent voted for the UK to remain. But that appears to primarily reflect the demographic characteristics of CFOs. According to the British Election Study (BES), 67 per cent of people who reported their work type as 'managers' and 66 per cent of people who reported the occupational classification of the head of the household as a 'manager' voted to remain, closer to the proportion of DMP members who were negative about Brexit (Figure 6). These groups are likely to be more comparable to DMP members, and the fact that these differences are small suggests that there is not a strong Brexit-related bias in the survey.

\footnotetext{
${ }^{13}$ The order in which panel members receive the three monthly questionnaires when they first join the panel is randomised. They then receive the monthly questionnaires in the same order in subsequent quarters.

${ }^{14}$ All results reported in this paper are weighted. To construct the weights, respondents are divided into 52 groups based on 13 industries and 4 size categories. The weight of each company is calculated as the total employment share accounted for by that group within the business population divided by the number of DMP respondents within that group. So, for example, all manufacturers with at least 250 employees (the largest size group) are given the same weight. Finance \& insurance and other production industries were initially excluded from the survey but have been part of the DMP since early 2018. These industries are given zero weight in that earlier period, with the weights of other sectors being proportionally scaled up.
} 


\section{Figure 6: Personal views on Brexit}

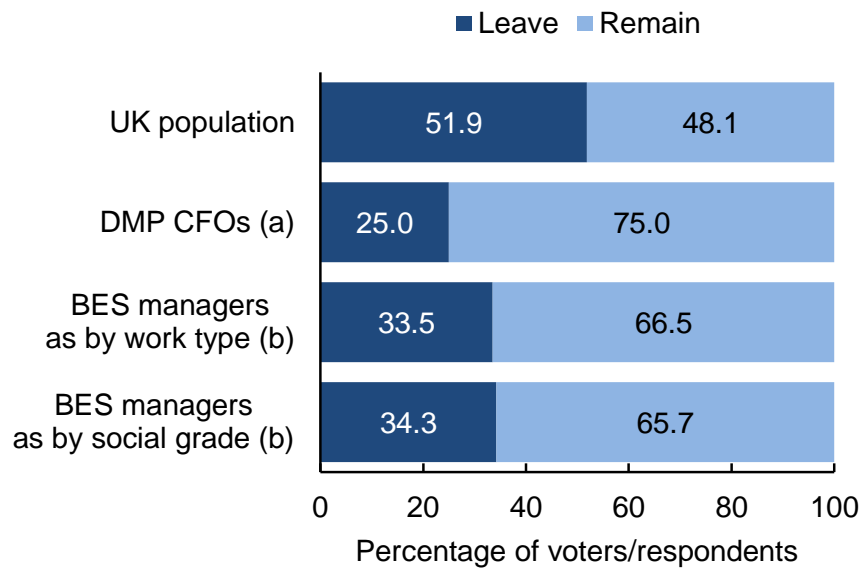

Source: Electoral Commission, DMP, British Election Study (BES) and authors' calculations.

(a) Personal views of DMP members at the time of the June 2016 referendum taken from February to April 2018 surveys. Respondents who did not have a strong view either way (4\%) were excluded. The question asked respondents about whether they view Brexit in a positive or negative way rather than how they voted in the referendum. (b) British Election Study data are self-reported referendum votes. To identify managers in the BES by their stated work type, only participants doing professional or higher technical work / higher managerial work that required at least degree-level qualifications or who worked as manager or senior administrator / intermediate managerial / professional (company director, finance manager, etc.) were included. To identify managers in the BES by their stated social grade, only participants who identified themselves as in a higher managerial, administrative and professional or intermediate managerial, administrative and professional occupation were included. Only respondents working and aged 66 or lower for males or aged 60 or lower for females were included. Respondents who did not know how they voted were excluded.

A second approach to assessing the extent of any possible Brexit-related bias in the survey is to analyse whether there is any relationship between the likelihood of a business participating in the survey and the EU referendum result in the local authority in which that business has its head office. Table 1 reports the results from linear probability regressions for whether a business has responded to at least one survey if it is part of the sampling frame. The first row of the table shows that there is not a statistically significant relationship between the share of leave votes in the referendum in the local authority where a firm is based and the probability that it has participated in the survey. This suggests that the DMP is not biased towards more proor anti-Brexit areas of the UK.

\section{Table 1: Linear probability models for propensity to respond to the DMP}

\begin{tabular}{l|cccc}
\hline & \multicolumn{4}{c}{ Ever responded to a survey if in the sampling frame } \\
& $(1)$ & $(2)$ & $(3)$ & $(4)$ \\
\hline Leave vote share & -0.022 & -0.026 & -0.020 & -0.018 \\
& $(0.019)$ & $(0.019)$ & $(0.019)$ & $(0.019)$ \\
Log of employment & & $0.017^{* * *}$ & $0.011^{* * *}$ & $0.011^{* * *}$ \\
& & $(0.002)$ & $(0.003)$ & $(0.003)$ \\
Log of sales & & $0.007^{* * *}$ & 0.004 \\
& & & $(0.002)$ & $(0.003)$ \\
Log of assets & & & 0.003 \\
& & & & $(0.002)$ \\
No. of observations & & & & \\
R-squared & 29,802 & 29,802 & 29,802 & 29,802 \\
& 0.010 & 0.013 & 0.014 & 0.014 \\
\hline
\end{tabular}

Source: Bureau van Dijk, DMP and authors' calculations.

Notes: Data as of October 2018. Two-digit UK SIC industry controls are included in all columns. Dependent variable equals 1 if a firm responded to any wave of the survey between September 2016 and October 2018 and 0 if it is part of the sampling frame but has never completed a survey. Firm characteristics are taken from Bureau van Dijk FAME data and are the latest available observations. 'Leave vote share' is the share of vote for leaving the EU in the local authority that a firm is headquartered in. There are 380 local authorities. Robust standard errors are given in parentheses. $* * * p<0.01$, ** $p<0.05, * p<0.1$. 


\section{What have we learnt about Brexit-related uncertainty?}

In this section, we use data from the DMP to examine a number of different aspects of the uncertainty created by Brexit. Although there are no comparable data from before the referendum, the DMP can still help to shed light on: (i) the extent to which Brexit has generated uncertainty for UK businesses; (ii) the types of firms that have been most affected; (iii) the nature of this uncertainty; and (iv) how this has changed since the referendum.

\section{(i) To what extent has Brexit generated uncertainty for UK businesses?}

Members of the DMP have been asked about the importance of Brexit as a source of uncertainty to their business on a number of occasions. ${ }^{15}$ Brexit appears to be an important source of uncertainty for many, but by no means all, businesses. Most recently, in the August to October 2018 surveys, 19 per cent of firms reported that Brexit was their largest current source of uncertainty, 29 per cent said that it was not the top source but in the top two or three, 39 per cent said it was one of many sources of uncertainty, with the remaining 13 per cent declaring that it was not important as a source of uncertainty (Figure 7). The proportion of firms citing Brexit as their top source of uncertainty was lower in earlier surveys, with around 40 per cent of firms reporting that it was either the largest current source of uncertainty or in their top two or three, compared with 48 per cent in the latest data.

\section{Figure 7: Brexit as a source of uncertainty}

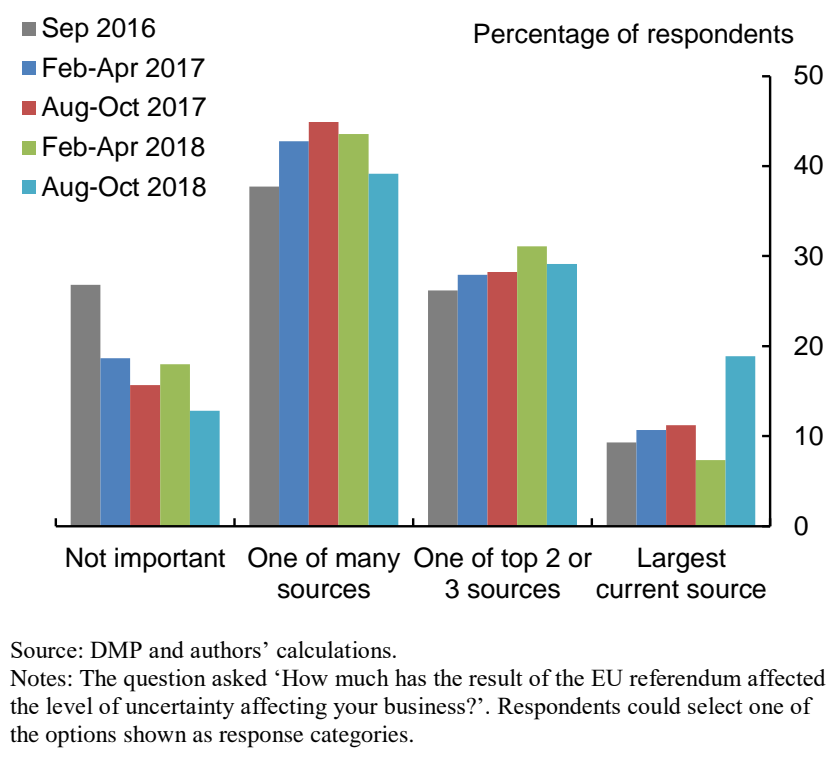

Figure 8: Brexit as a source of uncertainty by industry

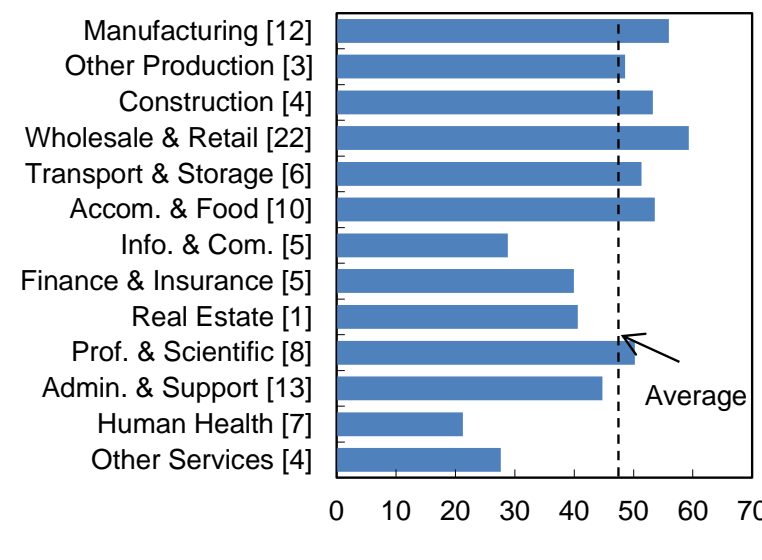

Percentage of firms with Brexit in top 3 uncertainty sources

Source: DMP and authors' calculations.

Note: The question asked 'How much has the result of the EU referendum affected the level of uncertainty affecting your business?'. Industries' employment shares are shown in square brackets. DMP data from August to October 2018 surveys.

\footnotetext{
${ }^{15}$ This question is typically asked to each panel member once every six months.
} 
The proportion of businesses that see Brexit as an important source of uncertainty varies across industries (Figure 8). In the August to October 2018 surveys, it was highest in wholesale \& retail and manufacturing and it was lowest in human health \& social work.

Businesses in industries that are more exposed to the EU through exports and their use of migrant labour are more likely to have reported that they have been affected by Brexit uncertainty. ${ }^{16}$ Figure 9 shows that there has been a positive correlation between the share of firms in each industry viewing Brexit as an important source of uncertainty and the proportion of their output that is exported to the EU. But the correlation here is not a perfect one either. For example, manufacturing has by far the highest share of output being exported to the EU, while the proportion of manufacturing firms uncertain about Brexit in the DMP has been only slightly higher than in a number of industries that export far less. Construction, for example, has little or no exports to the EU, but still had an above-average share of firms that see Brexit as an important source of uncertainty. In part, this could reflect concerns about the effects Brexit might have on the property market, as well as fears about the availability of EU migrant labour. The proportion of the workforce in construction who are EU nationals is above average. Figure 10 illustrates how there is a positive relationship between the importance of Brexit uncertainty and the share of workers who are EU nationals by industry, ${ }^{17}$ indicating that the availability of migrant labour is another source of uncertainty created by Brexit.

\section{Figure 9: Brexit as a source of uncertainty and the importance of EU exports, by industry}

Percentage of output exported to EU

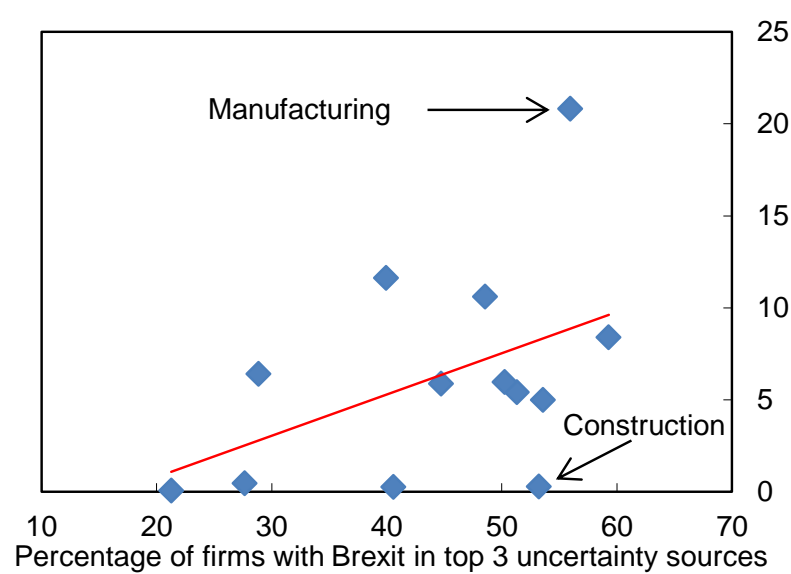

Source: DMP, Office for National Statistics and authors' calculations.

Notes: The question asked 'How much has the result of the EU referendum affected the level of uncertainty affecting your business?'. Shares of exports to the EU by industry are estimated using 2014 input-output tables and are at basic prices. DMP data from August to October 2018 surveys.

\section{Figure 10: Brexit as a source of uncertainty and the importance of EU migrant labour, by industry}

Percentage of workforce who are EU nationals

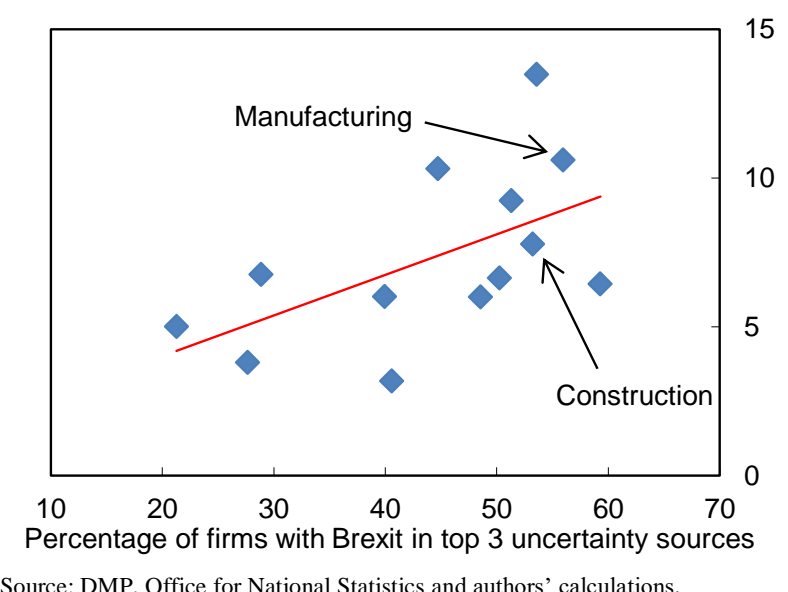

Source: DMP, Office for National Statistics and authors' calculations.

Notes: The question asked 'How much has the result of the EU referendum

affected the level of uncertainty affecting your business?'. Share of workforce who are EU nationals is estimated using the Labour Force Survey; data are an average for 2015 and 2016. DMP data from August to October 2018 surveys.

\footnotetext{
${ }^{16}$ Given the question asks about whether Brexit is an important source of uncertainty relative to other sources, differences between industries could also potentially be affected by differences in the extent of uncertainty from other sources across different sectors.

${ }^{17}$ The correlation coefficient is around 0.5, similar to that for the relationship between EU export shares and Brexit uncertainty shown in Figure 9.
} 
There are also some differences in the importance of Brexit uncertainty by firm size and by region. In the August to October 2018 surveys, the percentage of businesses that saw Brexit as being one of their top three sources of uncertainty was higher amongst larger firms, perhaps because they could be more internationally exposed (Figure 11). By region, Brexit uncertainty was estimated to be highest in the East Midlands and lowest in Scotland (Figure 12). But businesses, and in particular larger firms, do not operate in just one region of the UK; region here is defined only as where the business is headquartered. Excluding larger firms, defined as firms with at least 250 employees, might provide a better guide to how uncertainty is viewed by firms that primarily operate within a single region. When we do this, the picture changes: the share of firms citing Brexit as an important source of uncertainty is estimated to have been much higher in Northern Ireland than anywhere else in the UK (Figure 12). ${ }^{18}$

\section{Figure 11: Brexit as a source of uncertainty by firm size}

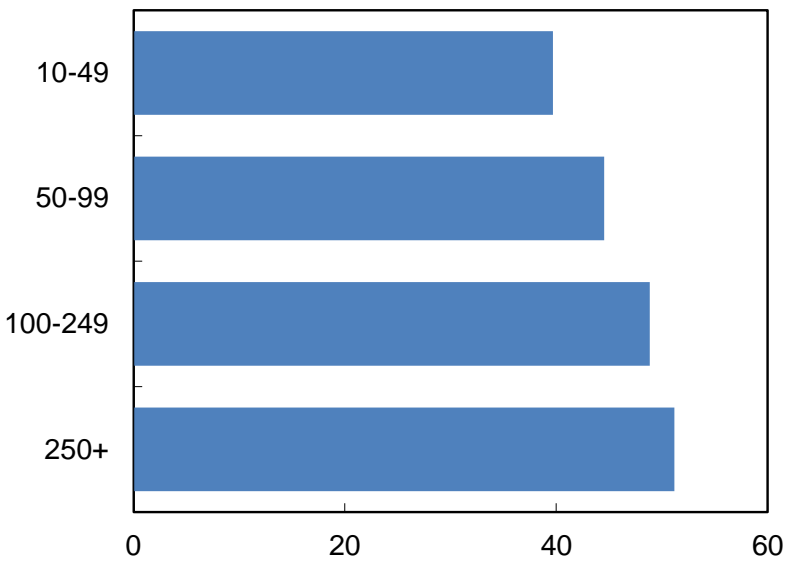

Percentage of firms with Brexit in top 3 uncertainty sources

Source: DMP and authors' calculations.

Notes: The question asked 'How much has the result of the EU referendum affected the level of uncertainty affecting your business?'. DMP data from August to October 2018 surveys.

\section{Figure 12: Brexit as a source of uncertainty by region}

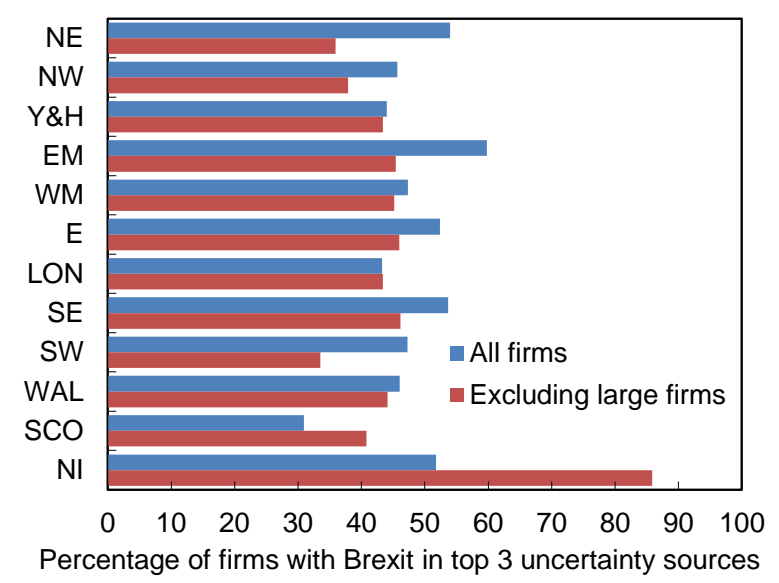

Source: DMP and authors' calculations.

Notes: The question asked 'How much has the result of the EU referendum affected the level of uncertainty affecting your business?'. Large firms are defined as those with 250 or more employees. Region is based on the location of head office. DMP data from August to October 2018 surveys.

\section{(iii) What is the nature of Brexit-related uncertainty?}

A key source of uncertainty for businesses surrounding Brexit is likely to be not knowing which economic model the UK will follow - for example, there is likely to be uncertainty around the extent of access to the Single Market, freedom of movement of labour, customs and other regulations - and what a given model might mean for the sales of an individual company. The fact that Brexit-related uncertainty has been higher in industries that are more dependent on exports to the EU and on EU migrant labour tells us that being unsure about how Brexit will affect future sales and not knowing how available migrant labour will be after Brexit are likely to be important reasons why businesses have been uncertain about the impact that Brexit will have.

\footnotetext{
${ }^{18}$ By region, the results are also sensitive to the weighting of the data. Unlike when analysing the data by industry or firm size, the region in which a firm is based is not used in the weighting process. In regions with smaller sample sizes in particular, the weighted results may therefore not be fully representative of all industries and firm sizes within that region and may be dominated by a small number of observations. On an unweighted basis and including firms of all sizes, the proportion of businesses citing Brexit as an important source of uncertainty was also highest in Northern Ireland.
} 
But the DMP also contains data that allow us to be more quantitative about the uncertainties surrounding variables such as future sales and costs.

On four occasions, DMP members have been asked to attach probabilities to different outcomes for the eventual impact that they expect Brexit to have on their sales. Most recently, in the August to October 2018 surveys, the average probability attached to Brexit eventually reducing sales was 39 per cent, with a 12 per cent chance of a positive impact (Figure 13). Similarly, panel members have been asked about the impact that they expect Brexit to have on other variables such as exports and labour costs. Brexit was expected to reduce exports and increase labour costs on average (Figure 14). As was the case with sales, individual businesses attached probabilities to a range of outcomes, indicating how they were uncertain about what will happen.

\section{Figure 13: Expected eventual impact of Brexit on sales}

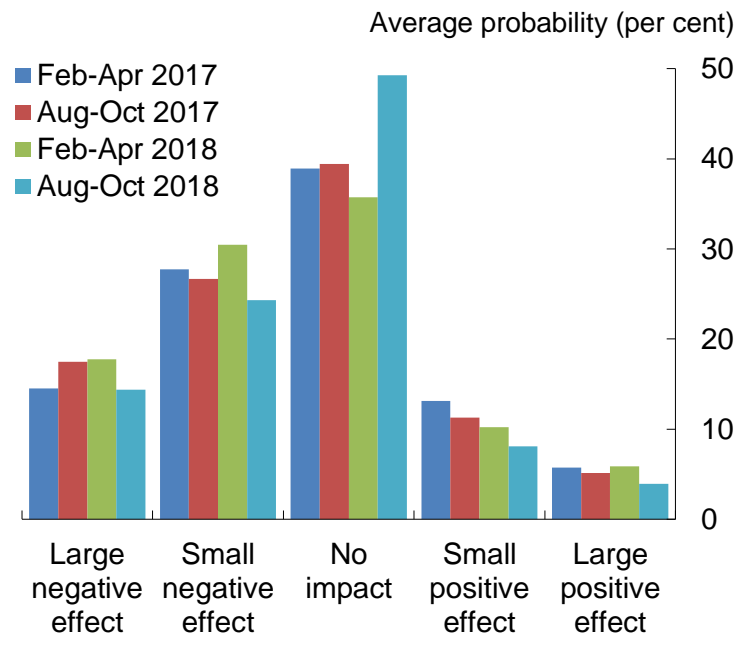

Source: DMP and authors' calculations.

Notes: The question asked 'How do you expect the eventual Brexit agreement to affect your sales once the UK has left the EU, compared to what would have been the case had the UK remained a member of the EU?'. A large positive/negative effect on sales corresponds to adding/subtracting 10 per cent or more to/from sales at home and abroad; a small effect is defined as less than 10 per cent. Prior to August 2018, this question also referred to the fact that the Prime Minister had said that the UK will leave the Single Market.

\section{Figure 14: Expected impact of Brexit on exports and labour costs}

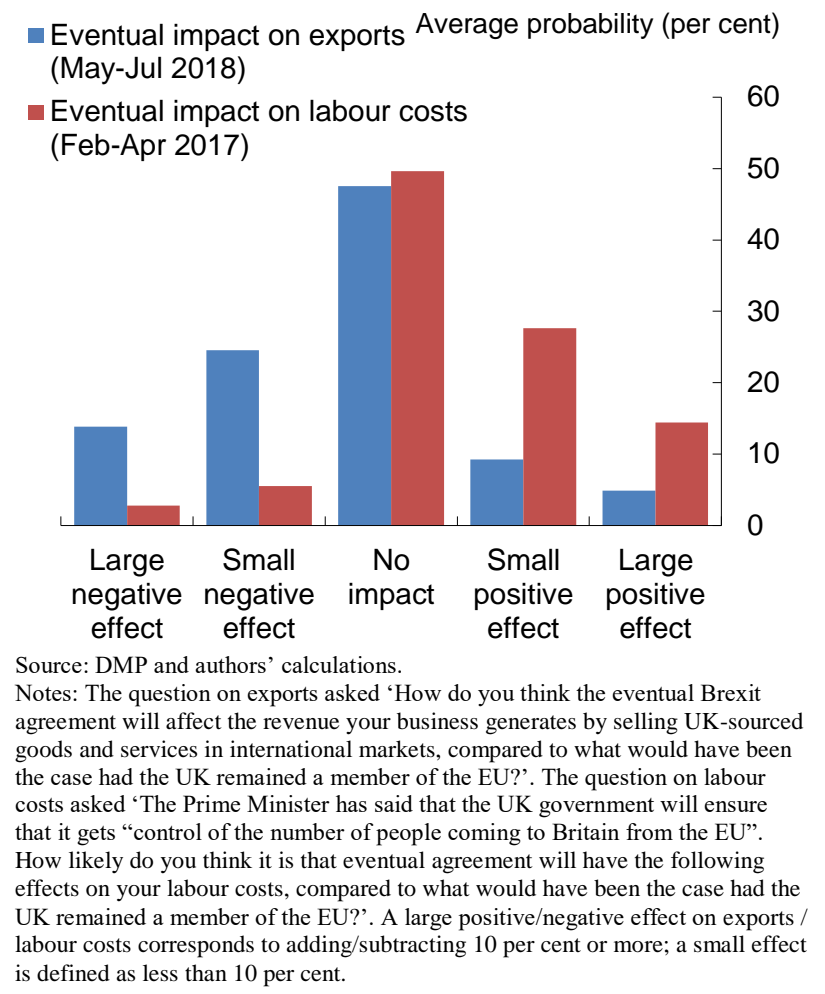

As the DMP asks respondents to attach average probabilities to different outcomes for the eventual impact of Brexit on sales, it is possible to calculate an indicative standard deviation of the expected sales impact by attaching some simple mid-points to the different response categories. These are shown in Figure 15 for firms split by their view on Brexit as a source of uncertainty, along with corresponding estimates of the uncertainty surrounding the effects on exports and labour costs.

Companies that viewed Brexit as an important source of uncertainty were also more uncertain about the eventual impact of Brexit on sales, exports and labour costs than those that saw Brexit as not being an important source of uncertainty. That is illustrated on Figure 15 by the average standard deviation of the 
expected effects of Brexit on these variables being higher for firms more affected by Brexit uncertainty (i.e. the first three lines from left to right on Figure 15 are upward sloping to some extent).

\section{Figure 15: Uncertainty around expected eventual impact of Brexit on exports, labour costs and sales and year-ahead sales growth, by Brexit as a source of uncertainty}

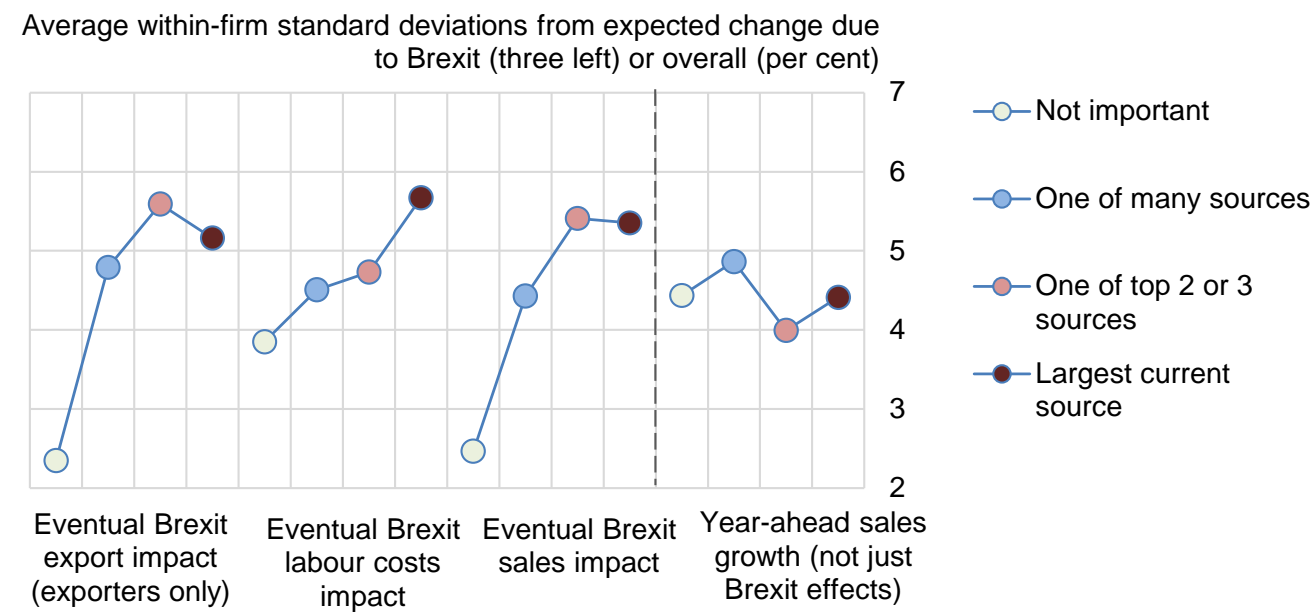

Source: DMP and authors' calculations.

Notes: The questions are as defined in notes to Figures 13 and 14. Graphs show mean standard deviation per firm. Brexit effects are calculated using mid-points of 0 per cent for no impact, 5 per cent for an effect of less than 10 per cent, and 15 per cent for an effect of 10 per cent or more. Eventual Brexit sales impact and year-ahead sales data are from August to October 2018 surveys, export data are from May to July 2018 surveys and labour costs data are from February to April 2017 surveys.

The analysis above focuses on the uncertainties surrounding the impact of Brexit in the longer term, but Brexit might also have created uncertainty about sales growth in the shorter term. The DMP can shed light on this too. When panel members are asked about their expectations for sales growth (and other variables such as prices, employment and investment), they are invited to give five scenarios for sales growth over the coming year - a lowest, low, medium, high and highest scenario - and then to attach probabilities to those scenarios. That allows a standard deviation of expected year-ahead sales growth to be calculated. This is a measure of uncertainty about sales growth more generally, although it could potentially be influenced by Brexit.

To date, there has been little difference in the standard deviation of expected year-ahead sales growth between firms that see Brexit as an important source of uncertainty and those that do not (as shown by the rightmost line on Figure 15 being relatively flat). This provides evidence that the uncertainties surrounding Brexit have been largely longer term in nature and have been less about short-term prospects, which is perhaps not surprising given that the UK had not yet left the EU when these data were collected.

The final aspect of Brexit uncertainty that the DMP can shed light on is around whether it will occur in a smooth way or not and about the timing of any transition arrangements. Figure 16 shows that in past surveys many DMP members have attached substantial probabilities to Brexit occurring in a disorderly manner. As of Spring 2018, the probability of a disorderly Brexit was thought to be higher by businesses that saw Brexit as an important source of uncertainty (Figure 17), indicating that concerns about whether Brexit will happen in an orderly way might be another reason why Brexit has created uncertainty for some. In data collected in 
late 2017 / early 2018, there was also a wide range of probabilities attached to when the UK will eventually leave the EU, after any transition deal (shown on Figure 19 later).

\section{Figure 16: Average probability of a disorderly Brexit}

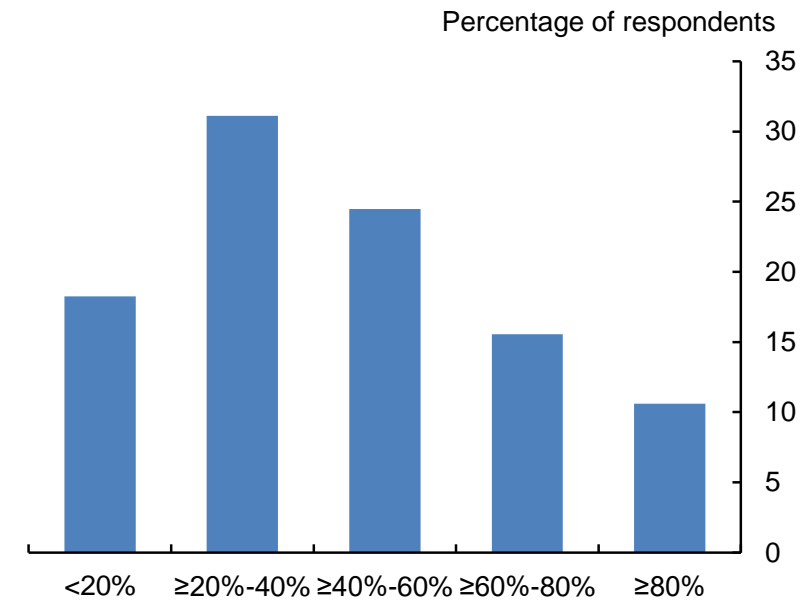

Source: DMP and authors' calculations.

Notes: The question asked 'What probability, in percent, do you attach to a

disorderly Brexit, whereby no deal is reached by the end of March 2019?'. DMP data from February to April 2018 surveys.

\section{Figure 17: Average probability of a disorderly Brexit by Brexit as a source of uncertainty}

Per cent

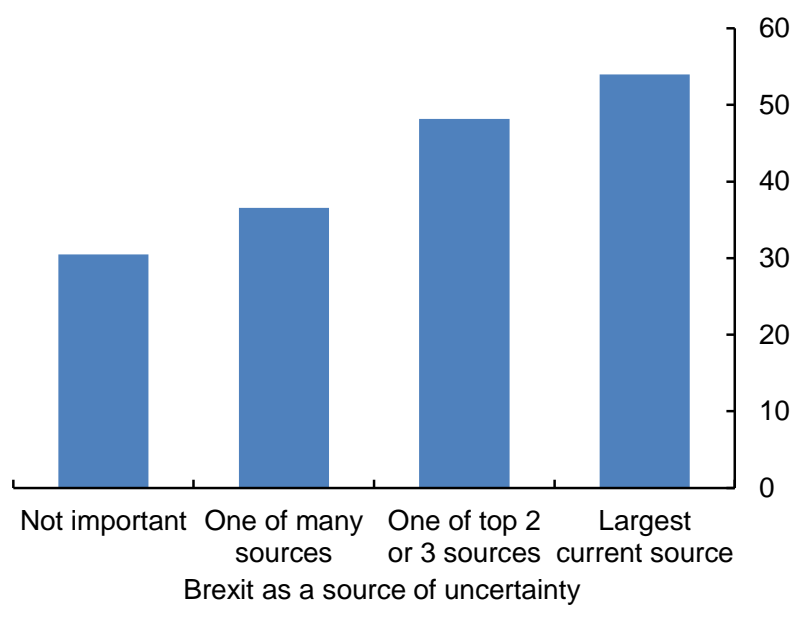

Source: DMP and authors' calculations.

Notes: The questions are as defined in notes to Figures 7 and 16. DMP data from February to April 2018 surveys.

\section{(iv) How has Brexit-related uncertainty changed since the referendum?}

In the two years following the Brexit referendum, there were not any large changes in the uncertainties that businesses were facing as the Brexit negotiations evolved. Figure 18 summarises the timeline of key events so far up until this paper was finalised in October 2018. The most substantial change in uncertainty came in the autumn of 2018, as the percentage of firms reporting that Brexit was in their top three sources of uncertainty rose from around 40 per cent to almost 50 per cent, although other uncertainty metrics saw less of a change (Table 2). This rise in uncertainty is likely to reflect the fact that a deal on the terms of withdrawal had not yet been agreed as the date at which the UK is due to leave the EU (29 March 2019) approached.

\section{Figure 18: Timeline of key Brexit dates as of October 2018}

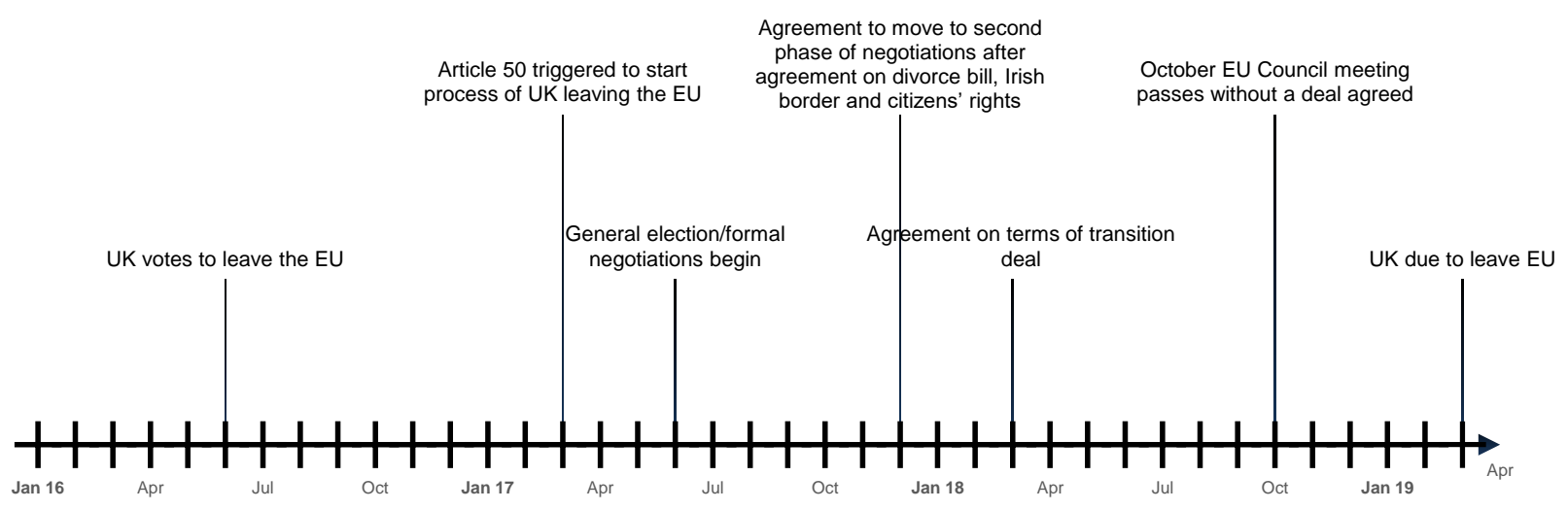




\begin{tabular}{l|cc}
\hline & $\begin{array}{c}\text { February-April } \\
2017\end{array}$ & $\begin{array}{c}\text { August-October } \\
2018\end{array}$ \\
\hline $\begin{array}{l}\text { Percentage of firms with Brexit in top three sources of } \\
\text { uncertainty }\end{array}$ & $39 \%$ & $48 \%$ \\
$\begin{array}{l}\text { Standard deviation of expected eventual impact of } \\
\text { Brexit on sales }\end{array}$ & $5.8 \%$ & $4.6 \%$ \\
$\begin{array}{l}\text { Standard deviation of expected year-ahead sales } \\
\text { growth }\end{array}$ & $4.4 \%$ & $4.6 \%$ \\
\hline
\end{tabular}

Source: DMP and authors' calculations.

There have been other signs of modest changes in uncertainty around key dates too - for example, the average probability attached to the UK leaving the EU before 2021, after any transition deal, fell after December 2017 following the agreement to move to the second stage of negotiations and the emergence of proposals for transition arrangements (Figure 19). Overall, the survey results suggest that, at the time of writing, businesses remained uncertain about what Brexit will entail.

\section{Figure 19: Expected timing of EU withdrawal after any transition period}

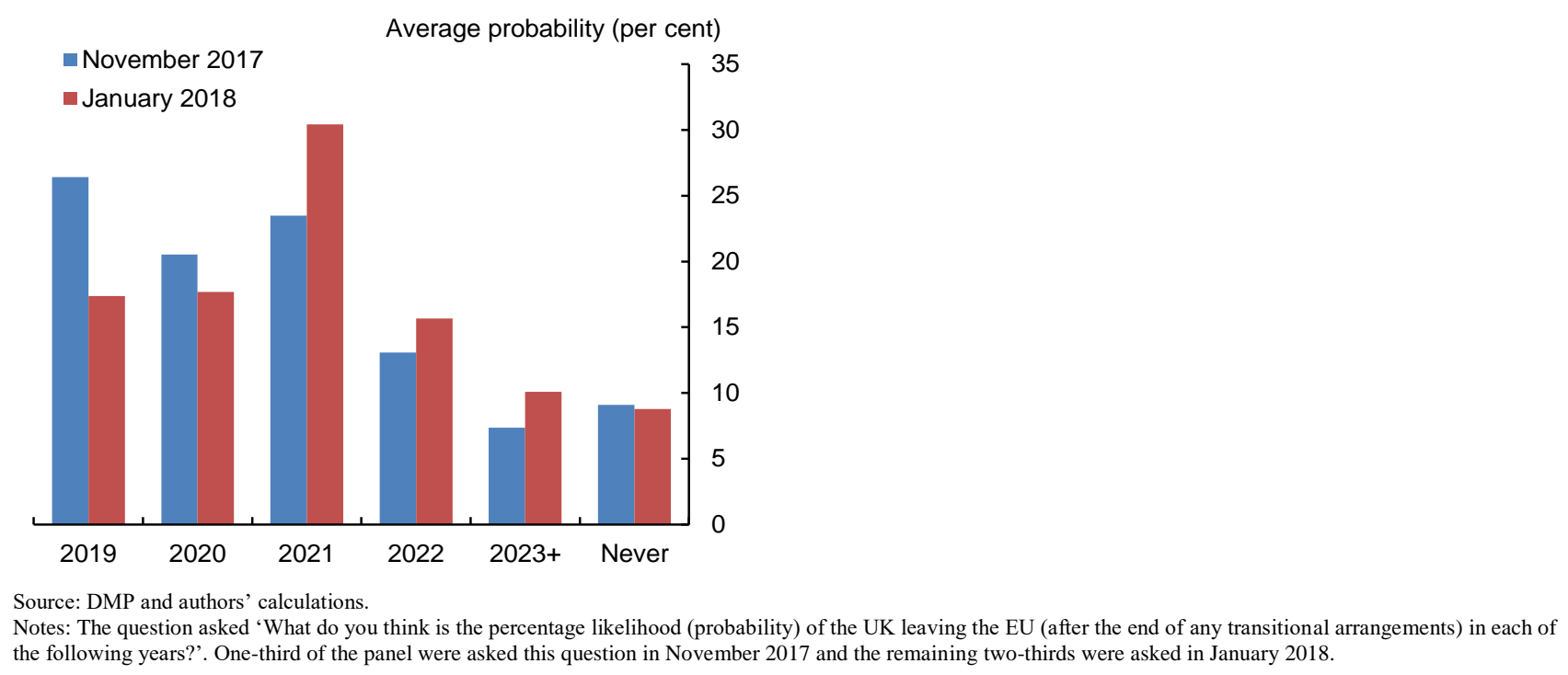

\section{Conclusions}

The UK's decision to leave the EU in the June 2016 referendum created substantial uncertainty for UK businesses around, for example, their future access to the Single Market, availability of labour, customs and product regulation and what all of this will mean for their sales. Brexit is a unique uncertainty shock and this limits the extent to which previous work can be used to understand the uncertainty it has created and how firms might respond. It is also closer to a pure second-moment uncertainty shock than many other past shocks because the uncertainty was created immediately by the referendum result, but the main impacts of Brexit will be largely felt over the longer term once the UK has left the EU, whereas many previous uncertainty shocks 
have been associated with recessions. The Decision Maker Panel is a new large and representative survey of firms that provides one way to explore the uncertainties associated with Brexit.

We use this unique new data set to investigate what we have learnt so far about the uncertainties created by Brexit for UK-based businesses. Results from the survey show that Brexit has provided a large and persistent uncertainty shock. In the two years after the referendum, an average of around 40 per cent of businesses reported that Brexit was in their top three current sources of uncertainty. Uncertainty has typically been higher in industries that are more dependent on trade with the EU and on EU migrant labour. We demonstrate how DMP responses suggest that the uncertainties around Brexit are primarily about the impact on businesses over the longer term rather than shorter term and that there has been substantial uncertainty about the timing of any transition arrangements and whether Brexit will take place in a smooth way. We also report that businesses think uncertainty rose in autumn 2018 and show how there have been some signs of modest changes in uncertainty around other key dates. Overall, substantial uncertainties remain.

The focus of this paper has been on using the DMP to better understand the uncertainty created by Brexit. But these data will be valuable in many other aspects of future research too; in particular, this information on uncertainty can also be linked with the responses of variables such as employment, investment and productivity to help establish what the uncertainty effects of Brexit on the economy have been. We leave this for future work. 


\section{References}

Alfaro, I., Bloom, N. and Lin, X. (2018), 'The finance-uncertainty multiplier', National Bureau of Economic Research (NBER), Working Paper no. 24571.

Altig, D., Barrero, J., Bloom, N., Bryant, M., Davis, S., Meyer, B. and Parker, N. (2018), 'The Atlanta Fed Survey of Business Uncertainty', mimeo.

Arellano, C., Bai, Y. and Kehoe, P. (2018), 'Financial frictions and fluctuations in volatility', Journal of Political Economy, forthcoming.

Baker, S. R., Bloom, N. and Davis, S. J. (2016), 'Measuring economic policy uncertainty', Quarterly Journal of Economics, vol. 131, pp. 1593-636.

Bansal, R. and Yaron, A. (2004), 'Risks for the long run: a potential resolution of asset pricing puzzles', Journal of Finance, vol. 59, pp. 1481-509.

Bernanke, B. (1983), 'Irreversibility, uncertainty, and cyclical investment', Quarterly Journal of Economics, vol. 98, pp. 85-106.

Bloom, N. (2009), 'The impact of uncertainty shocks', Econometrica, vol. 77, pp. 623-85.

- (2014), 'Fluctuations in uncertainty', Journal of Economic Perspectives, vol. 28, no. 2, pp. 153-76.

-, Mizen, P., Smietanka, P., Thwaites, G. and Young, G. (2017), 'Tracking the views of British businesses: evidence from the Decision Maker Panel', Bank of England Quarterly Bulletin, 2017 Q2, pp. 109-20.

—, Floetotto, M., Jaimovich, N., Saporta-Eksten, I. and Terry, S. (2018), 'Really uncertain business cycles', Econometrica, vol. 86, pp. 1031-65.

Brennan, M. and Schwartz, E. S. (1985), 'Evaluating natural resource investments', Journal of Business, vol. 58, pp. $135-57$.

Christiano, L., Motto, R. and Rostagno, M. (2014), 'Risk shocks', American Economic Review, vol. 104, pp. $27-65$.

Dixit, A. K. and Pindyck, R. S. (1994), Investment under Uncertainty, Princeton, NJ: Princeton University Press.

Fernández-Villaverde, J., Guerrón-Quintana, P., Rubio-Ramirez, J. F. and Uribe, M. (2011), 'Risk matters: the real effects of volatility shocks', American Economic Review, vol. 101, pp. 2530-61.

Fountas, S. and Karanasos, M. (2007), 'Inflation, output growth, and nominal and real uncertainty: empirical evidence for the G7', Journal of International Money and Finance, vol. 26, pp. 229-50.

Gilchrist, S., Sim, J. W. and Zakrajšek, E. (2014), 'Uncertainty, financial frictions, and investment dynamics', National Bureau of Economic Research (NBER), Working Paper no. 20038.

Guiso, L. and Parigi, G. (1999), 'Investment and demand uncertainty', Quarterly Journal of Economics, vol. 114, pp. 185-227.

Haddow, A., Hare, C., Hooley, J. and Shakir, T. (2013), 'Macroeconomic uncertainty: what is it, how can we measure it and why does it matter?', Bank of England Quarterly Bulletin, 2013 Q2, pp. 100-9.

Jurado, K., Ludvigson, S. C. and Ng, S. (2015), 'Measuring uncertainty', American Economic Review, vol. 105, pp. 1177-216.

McDonald, R. and Siegel, D. (1986), 'The value of waiting to invest', Journal of Money, Credit and Banking, vol. 101, pp. 707-28.

Redl, C. (2017), 'The impact of uncertainty shocks in the United Kingdom', Bank of England, Staff Working Paper no. 695.

Scotti, C. (2016), 'Surprise and uncertainty indexes: real-time aggregation of real-activity macrosurprises', Journal of Monetary Economics, vol. 82, pp. 1-19.

Smietanka, P., Bloom, N. and Mizen, P. (2018), 'Business investment, cash holding and uncertainty since the Great Financial Crisis’, Bank of England, Staff Working Paper no. 753. 